\title{
ANTICORPOS CONTRA Leptospira spp EM CERVOS-DO-PANTANAL (Blastocerus dichotomus) NA BACIA DO RIO PARANÁ, ESTADOS DE SÃO PAULO E MATOGROSSO DO SUL, BRASIL
}

\author{
ANTIBODIES TO Leptospira spp IN MASH DEER (Blastocerus dichotomus) IN THE PARANÁ \\ RIVER BASIN, STATES OF SÃO PAULO AND MATOGROSSO DO SUL, BRAZIL
}

\author{
G. R. O. GALLI ${ }^{1}$, N. A. ASSIS ${ }^{1}$, J. M. B. DUARTE ${ }^{1}$, R. GIRIO ${ }^{1}$
}

\begin{abstract}
RESUMO
Objetivou-se verificar a ocorrência de anticorpos contra Leptospira e avaliar espacialmente a dispersão de cervos-dopantanal (Blastocerus dichotomus) de vida livre, que fossem reagentes, na bacia do Rio Paraná, estados de São Paulo e Mato Grosso do Sul. Foram examinadas, por meio do teste de soroaglutinação microscópica (SAM), 217 amostras de soro sanguíneo (77 machos e 140 fêmeas) de cervos-do-pantanal capturados em seis localidades na bacia do rio Paraná, entre os estados de São Paulo e Mato Grosso do Sul. Desse total, 130 (59,91\%) amostras foram reagentes contra 12 diferentes sorovariedades de leptospiras patogênicas e 87 (40,09\%) foram não reagentes. As sorovariedades mais encontradas foram: Autumnalis (20,28\% dos animais examinados), Castellonis (13,36\%) e Hardjo (11,98\%). Os títulos sorológicos obtidos nas amostras reagentes variaram de 100 a 800 . Com relação ao sexo, $52(67,5 \%)$ machos e 78 $(55,7 \%)$ fêmeas foram reagentes, não sendo observada diferença estatisticamente significativa $(\mathrm{P}>0,05)$. A comparação entre os animais jovens e adultos sororreagentes revelou que houve diferença significativa $(\mathrm{P}<0,01)$ com relação à idade; 65,1\% dos adultos e 34,9\% dos jovens foram reagentes. Quanto ao local de captura, observou-se que as frequências de reagentes diferiram significativamente. A dispersão espacial, obtida por imagens de satélite aliadas às informações do geoposicionamento de cada cervo-do-pantanal capturado, mostrou distribuição de cervos-do-pantanal reagentes na área estudada.
\end{abstract}

PALAVRAS-CHAVE: Cervídeo. Leptospira spp. Mato Grosso do Sul. São Paulo.

\section{SUMMARY}

The objective was to verify the occurrence of antibodies to Leptospira and to evaluate the spatial dispersion of free living mash deer (Blastocerus dichotomus) reactors, in the basin of Paraná River, states of São Paulo and Mato Grosso do Sul. Through the microscopic agglutination test, we examined 217 serum samples (77 males and 140 females) of mash deer caught in six locations in the Paraná river basin between the states of São Paulo and Mato Grosso do Sul. From this total, $130(59.91 \%)$ samples reacted to 12 different serovars of pathogenic Leptospira, and 87 (40.09\%) did not react. The more prevalent serovars found were Autumnalis (20.28\% of the samples examined), Castellonis (13,36\%) and Hardjo (11,98\%). The serologic titers obtained in the reactive samples ranged from 100 to 800 . Regarding the gender, $52(67.5 \%)$ of the males and $78(55.7 \%)$ of the females were reactors. There was no statistically significant difference between genders $(\mathrm{P}>0.05)$. The comparison between the frequency of reactors among adult and among young animals revealed a significant difference $(\mathrm{P}<0.01) ; 65.1 \%$ of the adult and $34.9 \%$ of the young animals were reactors. A significant difference was also observed among the local where animals were captured. The spatial dispersion, obtained by satellite images and georeferenced information of each mash deer captured, showed the distribution of mash deer reactors on the area studied.

KEY-WORDS: Leptospira spp. Mash deer. São Paulo and Mato Grosso do Sul states.

\footnotetext{
${ }^{1}$ Universidade estadual Paulista "Júlio de Mesquita Filho" - Campus Jaboticabal. Via de Acesso Prof.Paulo Donato Castellane s/n CEP: 14884-900 Jaboticabal, SP
} 


\section{INTRODUÇ̃̃O}

O cervo-do-pantanal (Blastocerus dichotomus), que habita áreas de banhados e várzeas, é o maior cervídeo do Brasil (DUARTE, 1996). Atualmente a distribuição dessa espécie está fragmentada, por causa da ocupação das várzeas por agricultura e construções de usinas hidrelétricas.

O avanço da agropecuária e o crescimento acelerado de centros urbanos próximos às áreas naturais proporcionam o contato entre humanos, animais domésticos e as populações de animais selvagens. $\mathrm{O}$ estreito contato facilita a disseminação de agentes infecciosos a novos hospedeiros e para o ambiente, estabelecendo-se assim, novas relações entre hospedeiros e novos nichos ecológicos na cadeia epidemiológica de doenças. Com isso, enfermidades que eram consideradas controladas ou que já não possuíam importância epidemiológica podem dar origem a casos em animais selvagens, animais domésticos e seres humanos.

No último século tem ocorrido a diminuição da população de cervos-do-pantanal, e dentre os diversos motivos sugere-se que algumas enfermidades possam ter sido importantes nesse processo, como a febre aftosa, as orbiviroses (língua azul e doença epizoótica hemorrágica), a babesiose, a leptospirose e a neosporose, que estão entre as de maior frequência de anticorpos na população de cervos (DUARTE et al., 2012).
Tendo em vista a relação entre seres humanos, seus animais domésticos e as populações de animais selvagens de vida livre, pode-se considerar que os cervos-do-pantanal oriundos de áreas com presença de animais domésticos possam ter contato com patógenos comuns a esses animais, vindo a se tornar portadores de agentes etiológicos como a Leptospira spp.

No presente estudo pretendeu-se verificar a frequência de anticorpos contra Leptospira spp em cervos-do-pantanal de vida livre localizados nas proximidades do Rio Paraná entre a atual Barragem da Usina Hidrelétrica (UHE) Engenheiro Sérgio Motta, nos municípios de Rosana (SP) e Batayporã (MS), e a Barragem da UHE Engenheiro Souza Dias, nos municípios de Andradina (SP), Castilho (SP) e Três Lagoas (MS). Outro objetivo foi avaliar espacialmente a dispersão de cervos-do-pantanal (Blastocerus dichotomus) de vida livre reagentes a Leptospira na área estudada.

\section{MATERIAL E MÉTODOS}

\section{Área de Estudo}

O estudo foi realizado na bacia do Rio Paraná, entre os Estados do Mato Grosso do Sul e São Paulo, e no trecho entre as Usinas Hidrelétricas (UHE) Engenheiro Souza Dias (Jupiá) e Engenheiro Sérgio Motta (Porto Primavera) (Figura 1).

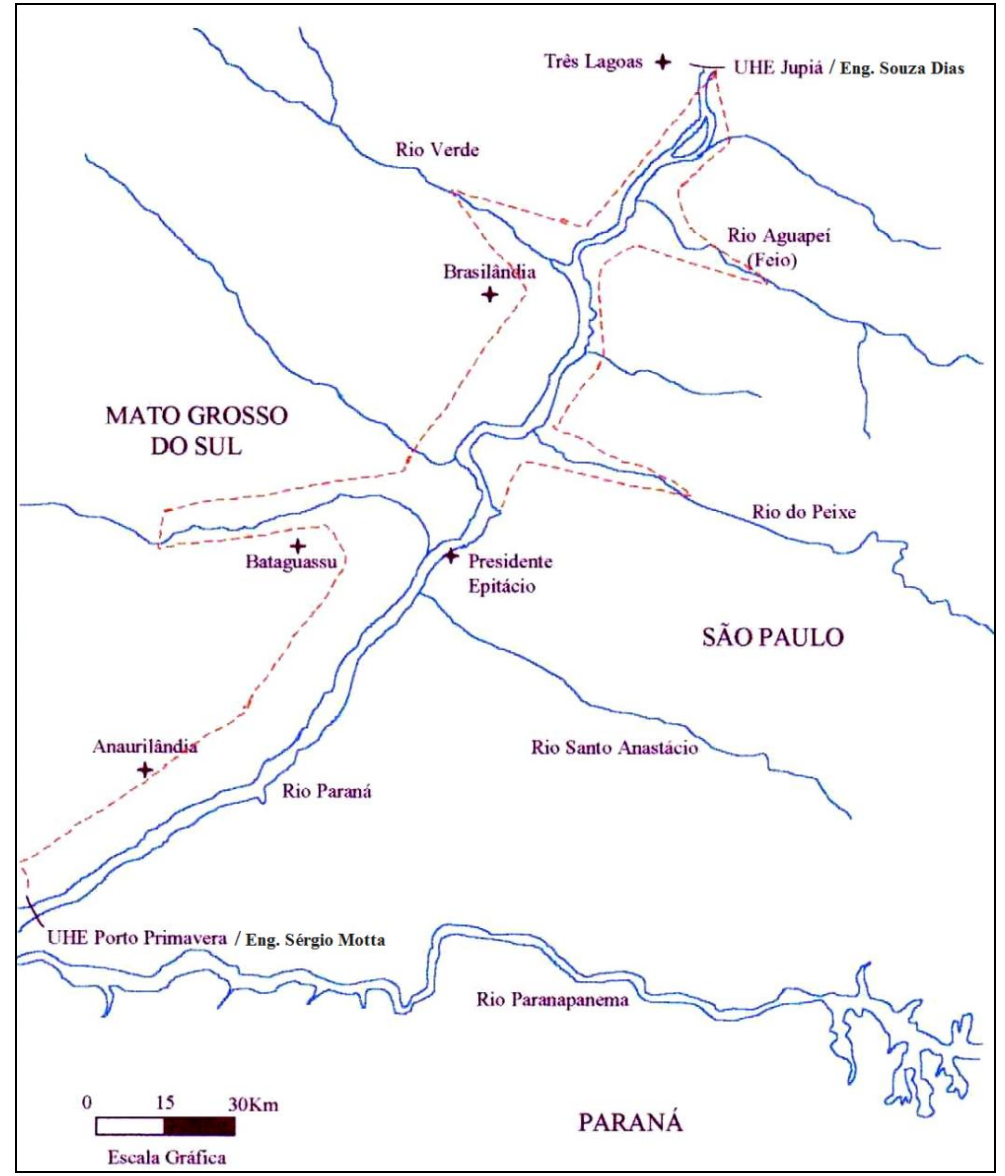

Figura 1 - Mapa representando trecho do Rio Paraná , local onde as amostras de sangue dos cervos-do-pantanal foram colhidas (Fonte: DUARTE, 2001). 


\section{Amostras}

Foram analisadas 217 amostras de soro sanguíneo de cervos-do-pantanal, pertencentes à soroteca de animais selvagens do Núcleo de Pesquisa e Conservação de Cervídeos (NUPECCE), da FCAV/UNESP, Câmpus de Jaboticabal obtidas entre 1998 e 2001, durante a realização e execução do projeto de despovoamento de cervídeos da bacia do Rio Paraná para a construção do complexo da UHE de Porto Primavera.

As capturas foram realizadas segundo metodologia descrita por DUARTE (2008), e as coordenadas do local foram estabelecidas utilizandose o sistema de posicionamento global (GPS). Para o presente estudo, os animais $(n=217)$ foram divididos em seis subgrupos de acordo com o local e o período da captura.

$\mathrm{Na}$ região entre as cidades de Quebracho e Bataguassu, foram realizadas duas capturas em tempos diferentes: uma antes da inundação, denominada MS1(1); e outra, dois anos após ter sido atingido o primeiro nível de enchimento do reservatório, denominada MS2 (2). No MS1, 101 animais foram capturados, e na captura MS2, 32 animais.

Situação semelhante ocorreu na região do Rio do Peixe, onde duas capturas foram definidas: uma antes do enchimento do reservatório, denominada de PX1 (3), e outra, dois anos após ter sido atingido o primeiro nível de enchimento do reservatório, denominada PX2 (4). Na PX1, 28 animais foram capturados, e na PX2, 12 animais.

$\mathrm{Na}$ região do rio Aguapeí (5) foram capturados 23 animais dois anos após ter sido atingido o primeiro nível de enchimento do reservatório. $\mathrm{Na}$ região do complexo Cisalpina (6) foram capturados 21 animais dois anos após ter sido atingido o primeiro nível de enchimento do reservatório.

\section{Processamento das amostras}

Para identificação dos animais sororreagentes foram utilizadas culturas de Leptospira spp. mantidas em meio líquido EMJH (Difco). Foi utilizada uma coleção de antígenos constituída por 25 sorovariedades (Andamana, Australis, Bratislava, Autumnalis, Butembo, Castellonis, Bataviae, Canicola, Whitcombi, Cynopteri, Sentot, Grippotyphosa, Hebdomadis, Copenhageni, Icterohaemorrhagiae, Javanica, Panama, Pomona, Pyrogenes, Hardjo, Wolffi, Mini, Patoc, Shermani e Tarassovi).

Foi utilizada a técnica de soroaglutinação microscópica (SAM), sendo a diluição inicial de 1/50. O critério adotado para considerar um soro como reagente foi o de no mínimo $50 \%$ de aglutinação, ou seja, metade das leptospiras aglutinadas no microscópio de campo escuro no aumento de 100 vezes. Os soros reagentes na diluição 1:50 foram reexaminados com oito diluições seriadas de razão dois e foram considerados positivas as amostras com título $\geq 100$ (OIE, 2008).

\section{Análise estatística}

As frequências de reagentes a Leptospira nas 217 amostras de soros examinadas foram comparadas segundo o sexo (77 machos e 140 fêmeas) e segundo a idade (175 adultos e 42 jovens). Para divisão por idade foram considerados jovens os animais que apresentavam até um ano e meio de vida, e adultos os animais que apresentavam idade superior a um ano e meio de vida. As frequências de reagentes entre as categorias sexo e idade e entre os locais de captura foram comparadas pelo teste do $\mathrm{X}^{2}$ (qui-quadrado de Pearson) ou pelo teste exato de Fisher. Todas as análises foram realizadas por meio do software R, de domínio público ( $\mathrm{R}$ Development Core Team, 2010).

\section{Geoprocessamento}

A imagem de satélite foi obtida através de download, autorizado no site governamental United States Geological Survey, Earth Resources Observation \& Science Center, o qual forneceu uma imagem do Satélite Lansat 1 (http://www.usgs.gov). As informações geográficas dos animais capturados juntamente com a imagem foram processadas pelo sistema de informação geográfica MapInfo Professional Version 10.0 Ten Build 7 (32-bit), que permitiu verificar a dispersão espacial dos animais que tiveram amostras reagentes e não reagentes.

\section{RESULTADOS}

Do total de 217 amostras examinadas, 130 $(59,91 \%)$ foram reagentes a diferentes sorovariedades de Leptospira spp. As sorovariedades de maior predominância foram Autumnalis com 44 (20,28\%), Castellonis com 29 (13,36\%), Hardjo com 26 (11,98\%) e Pyrogenes e Grippotyphosa com 7 (3,23\%) animais reagentes (Tabela 1 ).

Nas $130(59,91 \%)$ amostras reagentes, os títulos variaram entre 100 e 800 . No título de 100, a sorovariedade Autumnalis foi a mais frequente com 31,54\% (n=41) dos animais reagentes. Já no título de 200 foram: Castellonis (6,15\%), Hardjo (3,08\%) e Pyrogenes (3,08\%). Os títulos 400 e 800 foram detectados, respectivamente, para as sorovariedades Castellonis (5,38\%) e Hardjo (1,54\%) (Tabela 2). Ressalta-se que das 25 sorovariedades utilizadas como antígenos na prova de SAM, somente contra 12 foram detectados anticorpos.

Das áreas onde ocorreram as capturas dos animais, a que apresentou maior proporção de amostras sororreagentes foi a do Rio Aguapeí, com 22 (95,65\%) animais reagentes, que diferiu significativamente das outras $(\mathrm{P}<0,05)$, as quais não diferiram entre si (Tabela 3$)$.

Das 217 amostras analisadas, 77 eram de machos e 140 de fêmeas (Tabela 4). Destas, 52 $(67,5 \%)$ machos foram reagentes e $78(55,7 \%)$ fêmeas reagentes a uma ou mais sorovariedades de leptospiras (Tabela 4). O teste do qui-quadrado de Pearson mostrou que as proporções de reagentes entre machos e fêmeas não diferiram significativamente $(\mathrm{P}=0,12)$. Entre os animais jovens, $37,5 \%$ dos machos $(6 / 16)$ e $38,5 \%$ (10/26) das fêmeas foram reagentes, e essa diferença não foi estatisticamente significativa $(\mathrm{P}=$ 0,7518). Entre os adultos, 75,4\% (46/61) dos machos apresentaram títulos de anticorpos contra alguma sorovariedade, ao passo que a proporção de reagentes nas fêmeas desse grupo foi de 59,6\% (68/114), e essa 
diferença não foi significativa, embora estivesse perto da significância $(P=0,05505)$.

A comparação entre as proporções de reagentes nas duas faixas etárias mostra maior porcentagem de reagentes entre os adultos $(65,1 \% ; 114 / 175)$ do que entre os jovens $(38,1 \% ; 16 / 42)$, e essa diferença é estatisticamente significativa $(\mathrm{P}=0,002392)$. Entre os machos, 6 de 16 jovens $(37,5 \%)$ e 46 de 61 adultos $(75,4 \%)$ examinados foram reagentes a pelo menos uma sorovariedade, sendo essa diferença significativa $(\mathrm{P}=0,00981)$. Já nas fêmeas não se observou diferença significativa $(P=0,08118)$ entre a proporção de jovens
$(10 / 26 ; 38,5 \%)$ e a de adultos $(68 / 114 ; 59,6 \%)$ reagentes (Tabela 4 ).

Observam-se na Figura 2, marcados em amarelo, os locais onde ocorreram as capturas dos cervídeos na bacia do Rio Paraná. Os deslocamentos dos cervos-dopantanal ocorriam em grupos, em pastos onde também habitam rebanhos de bovinos.

Na Figura 3 apresenta-se a localização geográfica, ao longo da bacia do Rio Paraná, dos cervídeos capturados que se apresentaram reagentes contra pelo menos uma sorovariedade de Leptospira, marcação em vermelho.

Tabela 1 - Número e porcentagem de reagentes às sorovariedades de Leptospira spp. em amostras de cervos-do-pantanal capturados na bacia do Rio Paraná, estados de São Paulo e Mato Grosso do Sul, 1998-2001.

\begin{tabular}{cccc}
\hline SOROVARIEDADES & & \multicolumn{2}{c}{ Porcentagem } \\
\cline { 2 - 4 } & $\mathrm{N}^{\mathrm{o}}$ de reagentes & $\%^{\mathrm{a}}$ & 33,85 \\
Autumnalis & 44 & 20,28 & 22,31 \\
Castellonis & 29 & 13,36 & 20 \\
Hardjo & 26 & 11,98 & 5,38 \\
Pyrogenes & 7 & 3,23 & 5,38 \\
Grippotyphosa & 7 & 3,23 & 3,08 \\
Bratislava & 4 & 1,84 & 2,31 \\
Copenhageni & 3 & 1,38 & 2,31 \\
Pomona & 3 & 1,38 & 2,31 \\
Wolffi & 3 & 1,38 & 1,54 \\
Australis & 2 & 0,92 & 0,77 \\
Canicola & 1 & 0,46 & 0,77 \\
Javanica & 1 & 0,46 & 100 \\
\hline Total & 130 & 59,91 & \\
\hline
\end{tabular}

\%a: Porcentagem em relação ao total de animais examinados $(\mathrm{n}=217)$

$\%$ : Porcentagem em relação ao total sororreagentes $(n=130)$

Tabela 2 - Números e porcentagem de amostras reagentes, no teste de soroaglutinação microscópica, de acordo com a sorovariedade e o título sorológico encontrado nos cervos-do-pantanal, capturados na bacia do Rio Paraná, estados de São Paulo e Mato Grosso do Sul, 1998-2001.

\begin{tabular}{|c|c|c|c|c|c|c|c|c|c|}
\hline \multirow{3}{*}{ SOROVARIEDADES } & \multicolumn{8}{|c|}{ TITULOS } & \multirow{3}{*}{ Total } \\
\hline & \multicolumn{2}{|c|}{100} & \multicolumn{2}{|c|}{200} & \multicolumn{2}{|c|}{400} & \multicolumn{2}{|c|}{800} & \\
\hline & $\mathrm{N}^{\mathrm{o}}$ & $\%$ & $\mathrm{~N}^{\mathrm{o}}$ & $\%$ & $\mathrm{~N}^{\mathrm{o}}$ & $\%$ & $\mathrm{~N}^{\mathrm{o}}$ & $\%$ & \\
\hline Autumnalis & 41 & 31,54 & 3 & 2,31 & 0 & 0,00 & 0 & 0,00 & 44 \\
\hline Castellonis & 14 & 10,77 & 8 & 6,15 & 7 & 5,38 & 0 & 0,00 & 29 \\
\hline Hardjo & 19 & 14,62 & 4 & 3,08 & 1 & 0,77 & 2 & 1,54 & 26 \\
\hline Grippotyphosa & 4 & 3,08 & 2 & 1,54 & 1 & 0,77 & 0 & 0,00 & 7 \\
\hline Pyrogenes & 1 & 0,77 & 4 & 3,08 & 2 & 1,54 & 0 & 0,00 & 7 \\
\hline Bratislava & 1 & 0,77 & 3 & 2,31 & 0 & 0,00 & 0 & 0,00 & 4 \\
\hline Copenhageni & 2 & 1,54 & 1 & 0,77 & 0 & 0,00 & 0 & 0,00 & 3 \\
\hline Pomona & 1 & 0,77 & 2 & 1,54 & 0 & 0,00 & 0 & 0,00 & 3 \\
\hline Wolffi & 1 & 0,77 & 1 & 0,77 & 1 & 0,77 & 0 & 0,00 & 3 \\
\hline Australis & 1 & 0,77 & 1 & 0,77 & 0 & 0,00 & 0 & 0,00 & 2 \\
\hline Canicola & 1 & 0,77 & 0 & 0,00 & 0 & 0,00 & 0 & 0,00 & 1 \\
\hline Javanica & 1 & 0,77 & 0 & 0,00 & 0 & 0,00 & 0 & 0,00 & 1 \\
\hline TOTAL & 87 & 66,92 & 29 & 22,31 & 12 & 9,23 & 2 & 1,54 & 130 \\
\hline
\end{tabular}


Tabela 3 - Número e porcentagem de amostras reagentes e não reagentes dos cervos-do-pantanal capturados na bacia do Rio Paraná, estados de São Paulo e Mato Grosso do Sul, 1998 - 2001, de acordo com o local de captura.

\begin{tabular}{|c|c|c|c|c|c|}
\hline \multirow{2}{*}{ ÁREAS } & \multicolumn{2}{|c|}{ Reagentes } & \multicolumn{2}{|c|}{ Não Reagentes } & \multirow{2}{*}{ Total } \\
\hline & $\mathbf{N}^{\mathbf{o}}$ & $\%$ & $\mathbf{N}^{\mathbf{0}}$ & $\%$ & \\
\hline MS-01 & 56 & $55,45^{\mathrm{a}}$ & 45 & 44,55 & 101 \\
\hline MS-02 & 16 & $50,00^{\mathrm{a}}$ & 16 & 50,00 & 32 \\
\hline PX-01 & 16 & $57,14^{\mathrm{a}}$ & 12 & 42,86 & 28 \\
\hline PX-02 & 6 & $50,00^{\mathrm{a}}$ & 6 & 50,00 & 12 \\
\hline Aguapeí & 22 & $95,65^{\mathrm{b}}$ & 1 & 4,35 & 23 \\
\hline Cisalpina & 14 & $66,67^{\mathrm{a}}$ & 7 & 33,33 & 21 \\
\hline Total & 130 & 59,91 & 87 & 40,09 & 217 \\
\hline
\end{tabular}

Letra diferente indica diferença significativa $(\mathrm{P}<0,01)$.

Tabela 4 - Número de amostras examinadas e de amostras reagentes e porcentagem de reagentes contra Leptospira spp, de acordo com a idade e o sexo dos cervos-do-pantanal capturados na bacia do Rio Paraná, estados de São Paulo e Mato Grosso do Sul, 1998-2001.

\begin{tabular}{lccccccccc}
\hline Sexo & \multicolumn{3}{c}{ Macho } & \multicolumn{3}{c}{ Fêmea } & \multicolumn{3}{c}{ Total } \\
\hline Idade & Exam. & Reag. & $\%$ & Exam. & Reag. & $\%$ & Exam. & Reag. & $\%$ \\
\hline Jovem & 16 & 6 & $37,5^{\mathrm{b}, \mathrm{C}}$ & 26 & 10 & $38,5^{\mathrm{b}, \mathrm{E}}$ & 42 & 16 & $38,1^{\mathrm{A}}$ \\
Adulto & 61 & 46 & $75,4^{\mathrm{c}, \mathrm{D}}$ & 114 & 68 & $59,6^{\mathrm{c}, \mathrm{E}}$ & 175 & 114 & $65,1^{\mathrm{B}}$ \\
\hline Total & 77 & 52 & $67,5^{\mathrm{a}}$ & 140 & 78 & $55,7^{\mathrm{a}}$ & 217 & 130 & 59,9
\end{tabular}

Letras iguais minúsculas nas linhas e maiúsculas nas colunas indicam ausência de diferença significativa (P>0,05).

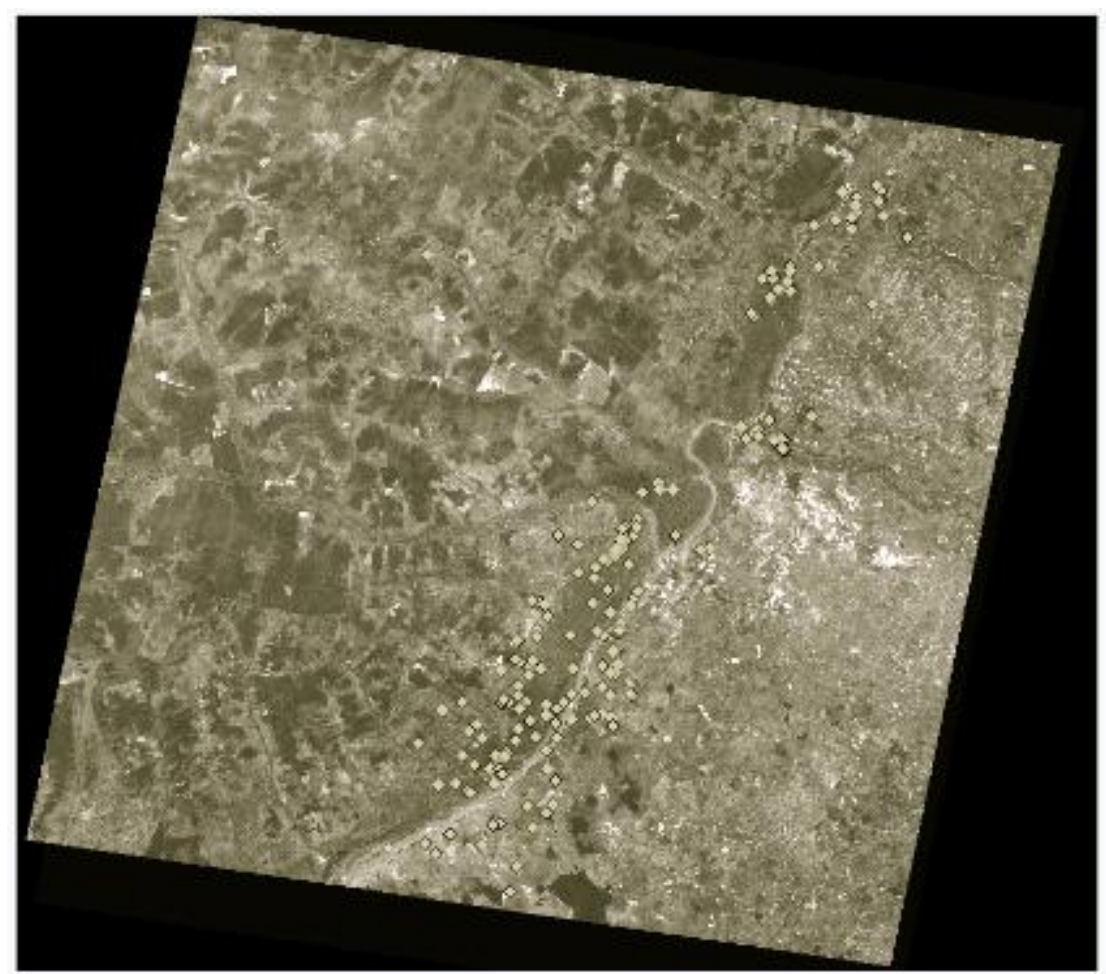

Figura 2 - Imagem de satélite com informações do georreferenciamento dos cervos-do-pantanal capturados na bacia do Rio Paraná, estados de São Paulo e Mato Grosso do Sul, 1998-2001 


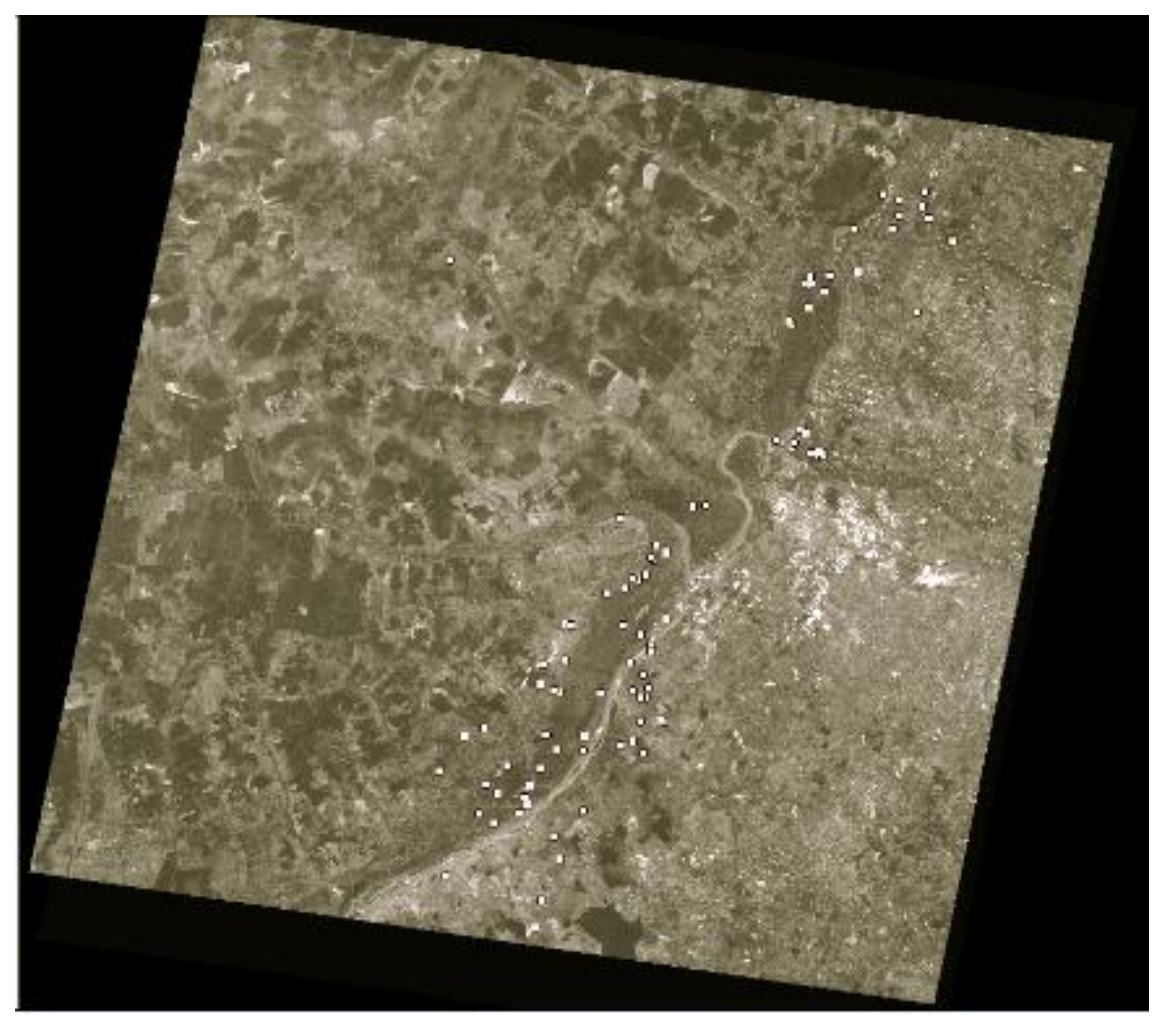

Figura 3 - Imagem de satélite com informações do georreferenciamento de cada amostra reagente contra Leptospira spp dos cervos-do-pantanal capturados na bacia do Rio Paraná, estados de São Paulo e Mato Grosso do Sul, 1998-2001.

\section{DISCUSSAO}

Observou-se que $59,9 \%$ das amostras examinadas foram reagentes a pelo menos uma sorovariedade de Leptospira patogênica. Outros trabalhos envolvendo pesquisa de anticorpos antiLeptospira spp em animais selvagens na região do Pantanal Sul-Mato-Grossense observaram frequências inferiores, Vieira et al. (2011) 5,9\% e Vieira et al. (2013) 23,28\%. No entanto, Jorge et al. (2011) encontraram resultados semelhantes ao do presente estudo, $42,7 \%$ de frequência em animais selvagens no pantanal Mato Grossense. Segundo Herholz et al. (2006), tais diferenças podem ser devidas ao fato de que a ocorrência e a transmissão são influenciadas por características do agente infeccioso, suscetibilidade de hospedeiros, concentração demográfica, movimentação, interação entre espécies e populações e, principalmente, pelas condições ambientais que permitem sua multiplicação e manutenção.

A sorovariedade Autumnalis foi a de maior frequência, $33,85 \%$, seguida pela Castellonis, com 22,31\%, e Hardjo, com 20,0\%. SILVA et al. (2010) também encontraram a sorovariedade Autumnalis como a mais frequente $(36,8 \%)$ em cervídeos em estado cativo. Igualmente, Jorge et al. (2011) encontraram como sorovar mais prevalente o Autumnalis em raposas e lobos-guarás no pantanal Mato-grossense, 39,53\% e 37,5\%, respectivamente.

Outros estudos em amostras de cervídeos de vida livre que habitam várias regiões mostraram resultados diferentes quanto às sorovariedades de maior frequência. MATHIAS et al. (1999) encontraram
Hardjo (24,0\%), GIRIO et al. (2004), Icterohaemorrhagiae e Copenhageni $(9,7 \%)$, TONIN et al. (2010), em um única amostra, encontraram Butembo e Bratislava, e ESPÍ et al. (2010) encontraram Pomona $(5,8 \%)$ e Muenchen $(2,6 \%)$. Essa diversidade de sorovariedades que podem infectar cervídeos talvez esteja relacionada com o ambiente, pelo fato de conviverem com outras espécies em estado selvagem ou ainda por dividirem o mesmo espaço com rebanhos de bovinos e/ou com roedores, entre eles as capivaras.

Os títulos sorológicos verificados nas amostras variaram de 100 a 800 . Esses resultados são similares aos de GIRIO et al. (2004) obtidos em amostras de veados-campeiros em estado feral da região de Nhecolândia, MS, e diferem dos encontrados, nos estados de Goiás e Mato Grosso do Sul, por MATHIAS et al. (1999), título máximo de 400, e por UHART et al. (2003) em amostras de veadoscampeiros de vida livre oriundas, respectivamente, dos estados de Goiás e Mato Grosso do Sul e da região dos Campos del Tuyú na Argentina, entre os anos de 1995 e 1998. Esses títulos sorológicos podem ser interpretados como uma infecção passageira ou uma imunidade de memória ou ainda um estágio inicial da leptospirose (FAINE, 1999).

Quanto ao sexo, os resultados não demonstraram diferença significativa entre a proporção de reagentes em machos e em fêmeas. Freitas et al. (2010) também não observaram associação entre a ocorrência da infecção por Leptospira spp e o fator sexo em população selvagem de queixadas (Tayassu pecari) na região sul do pantanal de Mato Grosso do Sul. 
Quando se comparou a porcentagem de amostras reagentes de cervídeos adultos com a de jovens constatou-se diferença significativa, resultado observado também por Freitas et al. (2010), que encontraram associação entre faixa etária e proporção de reagentes, sendo os adultos mais propensos à infecção. Esse resultado poderia estar ligado ao fato de animais mais velhos terem tido mais oportunidade de entrar em contato com o agente etiológico e, com isso, maior probabilidade de apresentar títulos de anticorpos (BLAHA, 1995; CORRÊA et al., 2004).

Foi possível identificar a área de captura dos 217 animais estudados, que estavam distribuídos em seis locais ao longo da bacia do Rio Paraná, entre as UHE de Porto Primavera e Jupiá, tanto na margem paulista, quanto na margem sul-mato-grossense. A área que apresentou maiores taxas foi Aguapeí, região com possível impacto ambiental, pois é a que está mais próxima da barragem da UHE de Jupiá. Esses achados mostram a possibilidade de disseminação das sorovariedades de Leptospira na bacia do rio Paraná entre os estados de São Paulo e Mato Grosso do Sul, como se pode verificar nas imagens de satélite com as informações do georreferenciamento sobre a dispersão dos cervos-do-pantanal que apresentaram amostras reagentes em toda a extensão da bacia (Figuras 2 e 3 ).

Pelos resultados obtidos no presente trabalho, pode-se concluir que os cervos-do-pantanal estão expostos à infecção natural pela Leptospira spp., visto que a maioria dos animais analisados foram positivos no teste de soroaglutinção, e que cervídeos reagentes contra Leptospira foram encontrados em grande extensão territorial, conforme se observa pelas imagens de satélite, demonstrando a disseminação e a dispersão do agente infeccioso.

\section{REFERÊNCIAS}

BLAHA, T. Epidemiologia especial veterinária. São Paulo: Acribia, 1995, p.128-136.

CORREAA, S. H. R.; VASCONCELLOS, S. A.; MORAIS, Z.; TEIXEIRA, A. A.; DIAS, R. A.; GUIMARÃES, M. A. B. V.; FERREIRA, F.; FEIRREIRA-NETO, J. S. Epidemiologia da leptospirose em animais silvestres na Fundação Parque Zoológico de São Paulo. Brazilian Journal of Veterinary Research and Animal Science, v.41, n.3, p.189-193, 2004.

DUARTE, J. M. B. Guia de identificação dos cervídeos brasileiros. Jaboticabal: FUNEP, 1996. 12p.

DUARTE, J. M. B. 2001. O cervo-do-pantanal (Blastocerus dichotomus) de Porto Primavera: resultado de dois anos de pesquisa. Relatório técnico. FUNEP/CESP: CD ROM.

DUARTE, J. M. B. A Technique for the capture of the free-ranging marsh deer (Blastocerus dichotomus). Journal of Zoo and Wildlife Medicine, v.39, n.4, p.596599, 2008.
DUARTE, J. M. B., PIOVEZAN, U., ZANETTI, E. S., RAMOS, H. G. C., TIEPOLO, L. M., VOGLIOTTI, A., OLIVEIRA, M. L., RODRIGUES, L. F., ALMEIDA, L. B. Avaliação do risco de extinção do cervo-do-pantanal Blastocerus dichotomus Illiger, 1815, no Brasil. Biodiversidade Brasileira, n.3, p.3-14, 2012.

ESPÍ, A.; PRIETO, J. M.; ALZAGA, V. Leptospiral antibodies in Iberian red deer (Cervus elaphus hispanicus), fallow deer (Dama dama) and European wild boar (Sus scrofa) in Asturias, Northern Spain. The Veterinary Journal, v.183, p.226-227, 2010.

FAINE, S. Leptospira and leptospirosis. 2ed., Melbourne: CRC Press, 1999, p.353.

FREITAS, T. P. T.; KEUROGHLIAN, A.; EATON, D. P.; FREITAS, E. B.; FIGUEIREDO, A.; NAKAZATO, L.; OLIVEIRA, J. M.; MIRANDA, F.; PAES, R. C. S.; MONTEIRO, L. A. R. C.; LIMA, J. V. B.; NETO, A. A. C.; DUTRA, V.; FREITAS, J. C. Prevalence of Leptospira interrogans antibodies in free-ranging Tayassu pecari of the Southern Pantanal, Brazil, an ecosystem where wildlife and cattle Interact. Tropical Animal Health and Production, v.42, p.1695-1703, 2010.

GIRIO, R. J. S.; PEREIRA, F. L. G.; MARCHIORIFILHO, M.; MATHIAS, L. A.; HERREIRA, R. C. P.; ALESSI, A. C.; GIRIO, T. M. S. Pesquisa de anticorpos contra Leptospira spp em animais silvestres e em estado feral da região de Nhecolândia, Mato Grosso do Sul, Brasil. Utilização de técnica de imuno-histoquímica para detecção do agente. Ciência Rural, v.34, n.1, p.165-169, 2004.

HERHOLZ, C.; JEMMI, T.; STARK, K.; GRIOT, C. Patterns of animal diseases and their control. Rivista Trimestrale di Sanità Pubblica Veterinaria,v.42, p.295303, 2006.

JORGE, R. S. P.; FERREIRA, F.; FERREIRA NETO, J. S.; VASCONCELLOS, S. A.; LIMA, E. S.; MORAIS, Z. M.; SOUZA, G. O. Exposure of free-ranging wild carnivores, horses and domestic dogs to Leptospira spp in the northern Pantanal, Brazil. Memórias do Instituto Oswaldo Cruz, v.106, n.4, p.441-444, 2011.

MATHIAS, L. A.; GIRIO, R. J. S.; DUARTE, J. M. B. Serosurvery for antibody against Brucella abortus and Leptospira interrogans in pampas deer from Brazil. Journal of Wildlife Diseases, v.35, n.1, p.112-114, 1999.

OIE - World Organization for Animal Health. Manual of diagnostic test and vaccines for terrestrial animals. $2008 . \quad$ Disponível em: <http://www.oie.int/fileadmin/Home/eng/Health_standar ds/tahm/2.01.09_LEPTO.pdf >. Acesso em 06 nov. 2013.

SILVA, J. F.; MATHIAS, L. A.; MAGAJEVSKI, F. S; WERTHER, K.; ASSIS, N. A.; GIRIO, R. J. S. Anticorposo contra Leptospira spp em animais domésticos e silvestres presentes no Campus universitário da FCAV, UNESP, Jaboticabal/SP. Ars Veterinaria, v.26, n.1, p.17-25, 2010. 
TONIN, A. A.; AZEVEDO, M. E. de; SILVA, A. S. da; SANTOS, L. G. dos; JUNIOR-MOURA, J. de. Infection in the Pampas deer (Ozotoceros bezoarticus) by four serotype of Leptospira interrogans. Comparative Clinical Pathology, p.1-2, 2010. <doi: 10.1007/S00580-010-1100-8>

UHART, M. M.; VILA, A. R.; BEADE, M. S.; BALCARCE, A.; KARESH, W.B. Health evaluation of Pampas Deer (Ozotoceros bezoarticus celer) at Campos del Tuyú Wildlife Reserve, Argentina. Journal of Wildlife Diseases, v.39, n.4, p.887-893. 2003.

VIEIRA, A. S.; ROSINHA, G. M. S.; OLIVEIRA, C. E.; VASCONCELLOS, S. A.; LIMA-BORGES, P. A.; TOMÁS, W. M.; MOURÃO, G. M.; LACERDA, A. C.; SOARES, C. O.; ARAÚJO, F. R.; PIOVEZAN, U.; ZUCCO, C. A.; PELLEGRIN, A. O. Survey of Leptospira spp in pampas deer (Ozotoceros bezoarticus) in the Pantanal wetlands of the state of Mato Grosso do Sul, Brazil by serology and polymerase chain reaction. Memórias do Instituto Oswaldo Cruz, v.106, n.6, p.763-768, 2011.
VIEIRA, A. S.; ROSINHA, G. M. S.; VASCONCELLOS, S. A.; MOARIS, Z. M.; VIANA, R. C.; OLIVEIRA, C. E.; SOARES, C. O.; ARAÚJO, F. R.; MOURÃO, G. M.; BIANCHI, R. C.; OLIFIERS, N.; RADEMAKER, V.; ROCHA, F. L.; PELLEGRIN, A.O. Identificação de mamíferos silvestres do pantanal Sul-Mato-Grossense portadores de Leptospira spp. Ciência Animal Brasileira, v.14, n.3, p.373-380, 2013. 